Скрипко A.H. / Skripko A.N. ${ }^{1}$

д-р техн. наук, профессор Мисун Л.B. / prof. Misun L.V., Ph.D. ${ }^{2}$

Przyjęty/Accepted/Принята: 20.11.2014;

Zrecenzowany/Reviewed/Рецензирована: 19.05.2015;

Opublikowany/Published/Опубликована: 30.06.2015;

\title{
Снижение влияния грозовых проявлений на объектах агропромышленного комплекса путем совершенствования характеристик их молниезащиты ${ }^{3}$
}

\author{
Reduction of Storm Consequences on the Agricultural Sector by Improvement to \\ Features of the Protection System Against Lightning Strikes
}

\author{
Redukcja wpływu zjawisk burzowych w obiektach sektora przemysłowo-rolnego \\ poprzez udoskonalenie właściwości systemów ochrony odgromowej
}

\begin{abstract}
АННОТАЦИЯ
Цель: Совершенствование средств молниезащиты от прямого удара молнии с учетом отрицательного опыта эксплуатации объектов хозяйствования при воздействии на них грозовых проявлений.

Введение: В Республике Беларусь ежегодно происходят пожары от ударов молнии, в результате которых уничтожаются производственные и общественные здания и сооружения, склады грубых кормов и льносырья, происходит гибель животных и птиц. В период с 2001 по 2013 года на территории республики произошло 46 пожаров в зданиях и сооружениях агропромышленного комплекса, 43 из которых произошло от прямого удара молнии, 3 - от вторичного проявления молнии. Так как наибольшую долю составляют пожары от прямых ударов молнии, то основными мерами, обеспечивающими защиту зданий и сооружений, являются молниеотводы [1-2]. В процессе эксплуатации молниеотводы за счет воздействия на них внешних факторов могут отклоняться от оси своей защиты. Из-за отклонения молниеотводов уменьшаются размеры зон защиты, что влияет на безопасное функционирование здания либо сооружения в момент удара молнии.

Методы: С целью изучения влияния отклонений молниеотводов на безопасное функционирование здания либо сооружения проведены исследования, в основу которых положены анализ статистических сведений по пожарам от ударов молнии, натурные наблюдения по отклонениям молниеотвода от оси защиты. На основании проведенных пассивных экспериментов разработаны математическая модель для прогнозирования устойчивого функционирования здания либо сооружения к возникновению пожаров от грозовых проявлений и математическая модель эффективной работы молниеотвода. Предложено техническое решение по устройству молниеотвода, обеспечивающего эффективную защиту объекта от прямого удара молнии. Проведены наблюдения за молниеотводом с регистрацией его отклонений от оси защиты.

Выводы: Обоснованы оптимальные технические характеристики средства защиты от прямого удара молнии, на основе которых разработан экспериментальный образец молниеотвода. Установлены предельные отклонения молниеотвода с целью разработки изменений в методологию определения зоны защиты молниеотводов, внесения соответствующих поправок в требования по противопожарному нормированию и стандартизации республики.

Значение для практики: Применительно к объектам хозяйствования: разработка технического решения в области молниезащиты, позволяющего обеспечивать стабильное и устойчивое положение молниеотвода относительно оси защиты, исключать уменьшение размеров зон защиты молниеотвода.
\end{abstract}

\footnotetext{
Учреждение „Научно-исследовательский институт пожарной безопасности и проблем чрезвычайных ситуаций” Министерства по чрезвычайным ситуациям Республики Беларусь, г. Минск; rifs.minsk@gmail.com / The Establishment "Research Institute of Fire Safety and Emergencies" of the Ministry for Emergency Situations of the Republic of Belarus, Minsk;

2 Учреждение образования „Белорусский государственный аграрный технический университет”, г. Минск / Belarusian State Agrarian Technical University, Minsk;

3 Авторы внесли одинаковый вклад в создание статьи / The authors contributed equally to this article;
} 
Ключевые слова: молния, молниезащита, молниеотвод, пожар, объект агропромышленного комплекса

Вид статьи: обзорная статья

\section{A BSTRACT}

Aim: Identification of solutions, which increase the effectiveness of protection against direct lightning strikes, by taking account of past experience associated with agricultural property, which was exposed to the impact of storms.

Introduction: Each year, in the Republic of Belarus, many fires are caused by lightning strikes. As a result buildings used by the public and for industrial purposes are exposed to damage. These include storage facilities for flax and fodder. Additionally, animals and birds die. During the years 2001-2013 there were 46 fires in Belarus, which affected buildings and items from the agro-industrial sector, of which 43 were as the result of direct lightning strikes and 3 related to secondary causes. The biggest proportion of fires were caused by direct lightning strikes. The basic approach used to protect buildings from lightning strikes is by utilising lightning conductors [1-2]. During a period of use, protective properties of lightning conductors may undergo a change, caused by the influence of external factors. Such a change may reduce the size of a protected area with a consequential impact on the safety of a building or other item in the vicinity at the moment of a lightning strike.

Methods: In order to examine the impact on the safety of buildings and other property, caused by changes to properties of lightning conductors, research was performed with the aid of data analysis, of fires caused by lightning strikes and by observation of changes to properties of lightning conductors. Based on passive experiments a mathematical model was developed for use in forecasting, to determine the potential for property to avoid the consequences of fires caused by storms and a model, which could describe the effective operation of a lightning conductor. A technical solution was proposed for the construction of a lightning conductor, which would protect property from a direct lightning strike. A study of lightning conductors was performed, including the registration of changes to their protection properties.

Conclusions: The choice of optimum technical data, for a protection device against direct lightning strikes, was justified. This data provided a basis for the development of an experimental lightning conductor model. Furthermore, research identified limit values applicable to changes in the properties of lightning conductors, with the aim of modifying methods of describing the protection range of lightning conductors and introduction of appropriate amendments to fire prevention regulations and norms in Belarus.

Implications for practice: The development of a technical solution, to deal with protection against lightning strikes, particularly for business properties, provides a level of stable and lasting security and eliminates the problem associated with a reduction in the protective range of lightning conductors.

Keywords: lightning, lightning protection, lightning conductor, fire, agricultural property

Type of article: review article

\section{A BSTRAKT}

Cel: Wskazanie rozwiązań zwiększających efektywność środków ochrony przeciw bezpośredniemu uderzeniu pioruna z uwzględnieniem negatywnych doświadczeń z eksploatacji obiektów gospodarczych związanych z oddziaływaniem na nie zjawisk burzowych.

Wprowadzenie: W Republice Białorusi co roku dochodzi do pożarów spowodowanych uderzeniem piorunów. W wyniku tych pożarów zniszczeniu ulegają budynki produkcyjne oraz budynki i obiekty użyteczności publicznej, magazyny paszy objętościowej i lnu, giną zwierzęta, w tym ptaki. W latach 2001-2013 na terytorium Białorusi doszło do 46 pożarów w budynkach i obiektach sektora przemysłowo-rolnego, 43 z nich wskutek bezpośredniego uderzenia pioruna, a 3 od jego wtórnego oddziaływania. Największy odsetek stanowią pożary powstałe wskutek bezpośredniego uderzenia pioruna. Podstawowymi metodami ochrony obiektów od tego rodzaju zagrożenia są piorunochrony [1-2]. W czasie eksploatacji piorunochronów, z uwagi na oddziaływanie czynników zewnętrznych, ich właściwości ochronne mogą ulec zmianom. Odchylenia piorunochronów mogą powodować zawężenie strefy objętej ochroną, wpływając w ten sposób na bezpieczeństwo budynku lub obiektu w momencie uderzenia piorunu.

Metody: Aby zbadać wpływ zmian właściwości piorunochronów na bezpieczeństwo budynków i obiektów, przeprowadzone zostały badania, których podstawą była analiza danych statystycznych na temat pożarów powstałych wskutek uderzenia pioruna oraz obserwacje zmian właściwości piorunochronów. Na podstawie przeprowadzonych biernych eksperymentów opracowany został model matematyczny do prognozowania odporności budynków lub obiektów na pożary powstałe w wyniku zjawisk burzowych oraz model matematyczny skutecznej pracy piorunochronu. Zaproponowano rozwiązanie techniczne budowy piorunochronu, który zapewniłby ochronę obiektu przed bezpośrednim uderzeniem piorunu. Przeprowadzono obserwacje piorunochronu, w tym rejestrację jego odchyleń od osi ochrony. Wyniki: Uzasadniono dobór optymalnych parametrów technicznych dla urządzenia zabezpieczającego przed bezpośrednim uderzeniem pioruna, na podstawie których opracowano model eksperymentalny piorunochronu. Określono wartości graniczne dla zmian właściwości piorunochronu w celu opracowania zmian metodologii określania zasięgu ochrony piorunochronów, wprowadzenia odpowiednich poprawek w wymaganiach norm przeciwpożarowych i standaryzacji na Białorusi.

Znaczenie dla praktyki: Stosowanie w obiektach gospodarczych: opracowanie rozwiązania technicznego w zakresie ochrony odgromowej, zapewniającego stabilną i trwałą ochronę, wyeliminowanie problemu zmniejszenia zasięgu ochrony piorunochronu.

Słowa kluczowe: piorun, ochrona odgromowa, piorunochron, pożar, obiekt sektora przemysłowo-rolnego

Typ artykułu: artykuł przeglądowy

\section{1. Введение}

За грозовые периоды времени, начиная с 2001 по 2013 годы, на территории Республики Беларусь произошло 2554 случая пожаров. Непосредственно от прямых ударов молнии произошло 2470 пожара, 84 пожара - от вторичного проявления молнии, из них 
в $4 \%$ случаев причиной пожара стал занос высокого потенциала, в 3 \% - электростатическая и электромагнитная индукция. В ходе изучения пожаров на животноводческих фермах и комплексах, вызванных грозовыми проявлениями, установлено, что за период с 2001 по 2013 года на территории республики произошло 46 пожаров, 43 из которых произошло от прямого удара молнии, 3 - от вторичного проявления молнии [3]. Проведенный анализ пожаров, вызванных грозовыми проявлениями, условий эксплуатации молниезащиты, требований действующих технических нормативных правовых актов позволяет сделать вывод о необходимости выработки более действенных мер по снижению влияния грозовых проявлений на объекты агропромышленного комплекса и, в первую очередь, направленных на повышение эффективности эксплуатации и работоспособности молниезащиты в соответствии с $[1,2]$.

Основными задачами исследований послужили:

- изучение пространственно-временного распределения пожаров на территории Республики Беларусь и их причинно-следственная связь с грозовыми проявлениями на объектах агропромышленного комплекса;

- разработка модели устойчивого функционирования объекта при воздействии на него грозовых проявлений (в том числе устойчивого функционирования молниезащиты);

- разработка молниеотвода с повышенными характеристиками устойчивости функционирования.

\section{2. Изучение факторов безопасного функционирования объекта к возникновению пожаров от грозовых разрядов}

Так как практически невозможно четко сформулировать критерий оценки объекта исследования, его взаимодействие с окружающей средой (при отсутствии четкого формального описания процесса взаимодействия) необходимость устройства молниезащиты предложено определять посредством имитационное моделирования, в основе которого лежит эксперимент. Известно, что безопасное функционирование объекта, во время грозовых проявлений, зависит от различного рода и множества факторов. При сборе и анализе факторов внимание уделялось объектам, на которых произошел пожар от удара молнии, действующим объектам агропромышленного комплекса с устройством молниезащиты выполненных с нарушением и без него. В ходе анализа статистических сведений по пожарам выявлено более 30 факторов влияющих на устойчивость объекта к возникновению пожаров от грозовых разрядов. Факторы были разделены на группы (табл. 1): $\mathrm{X}$ - факторы, которые влияют на поведение системы «объект защиты» (далее - система), и которыми возможно управлять;

Z - факторы, которые влияют на систему, и которыми управлять не возможно вследствие ограничений (технических, технологических, экономических: сила тока молнии, частота удара молнии и т.д.);

Q - факторы, которые влияют на поведение системы, но управление ими на данном этапе развития технических наук не возможно (полярность молнии).

Таблица 1. Сводная таблица факторов устойчивого функционирования объекта к возникновению пожаров от грозовых разрядов Table 1. Pivot table of the factors determining sustainable operation of the facility when exposed to lightning discharges

\begin{tabular}{|c|c|c|}
\hline $\begin{array}{l}\text { № п.п / } \\
\text { No. }\end{array}$ & $\begin{array}{c}\text { Обозначения } \\
\text { факторов / } \\
\text { Symbol of a factor }\end{array}$ & $\begin{array}{c}\text { Наименование факторов, единица измерения / } \\
\text { Name of a factor, unit }\end{array}$ \\
\hline 1 & 2 & 3 \\
\hline \multicolumn{3}{|r|}{ 1. Факторы типа X / Factors type X } \\
\hline 1.1 & $\mathrm{X}$ & Высота объекта защиты, м / Height of the protected facility, m \\
\hline 1.2 & $\mathrm{X}$ & Площадь объекта защиты, м / Area of the protected facility, m \\
\hline 1.3 & $\mathrm{X}$ & Степень огнестойкости объекта защиты / Fire resistance of the protected facility \\
\hline 1.4 & $\mathrm{X}$ & $\begin{array}{l}\text { Размещение молниеотвода на/возле объекте(а) защиты / Location of a lightning } \\
\text { conductor on/near the protected facility }\end{array}$ \\
\hline 1.5 & $\mathrm{X}$ & Форма кровли объекта защиты / Shape of the roof of the protected facility \\
\hline 1.6 & $\mathrm{X}$ & $\begin{array}{l}\text { Отношение высоты молниеотвода к его радиусу зоны защиты, м/м / Relation between } \\
\text { the of height of a lightning conductor and its radius of the lightning protection zone, } \mathrm{m} / \mathrm{m}\end{array}$ \\
\hline 1.7 & $\mathrm{X}$ & Сечение молниеприемника, мм / Cross-section of a lightning conductor, mm \\
\hline 1.8 & $\mathrm{X}$ & Длина заземлителя, м / Length of the earthing, m \\
\hline 1.9 & $\mathrm{X}$ & $\begin{array}{l}\text { Отношение допустимого для заземлителя молниеотвода сопротивления к удельному } \\
\text { сопротивлению грунта, Ом/Ом·м / Relation between between the earthing resistance } \\
\text { acceptable for conductors and soil resistivity, } \Omega / \Omega \cdot \mathrm{m}(\ldots)\end{array}$ \\
\hline 1.10 & $\mathrm{X}$ & Удельное сопротивление грунта, Ом·м / Soil resistivity, $\Omega \cdot \mathrm{m}$ \\
\hline 1.11 & $\mathrm{X}$ & Тип грунта / Type of soil \\
\hline
\end{tabular}




\begin{tabular}{|c|c|c|}
\hline $\begin{array}{l}\text { № п.п / } \\
\text { No. }\end{array}$ & $\begin{array}{c}\text { Обозначения } \\
\text { факторов / } \\
\text { Symbol of a factor }\end{array}$ & $\begin{array}{c}\text { Наименование факторов, единица измерения / } \\
\text { Name of a factor, unit }\end{array}$ \\
\hline 1 & 2 & 3 \\
\hline 1.12 & $\mathrm{X}$ & $\begin{array}{l}\text { Отношение длины заземлителя к допустимому сопротивлению, м/Ом / Relation } \\
\text { between the length of the earthing and the maximum acceptable resistance, } \mathrm{m} / \Omega\end{array}$ \\
\hline 1.13 & $\mathrm{X}$ & Площадь заземлителя, $\mathrm{m}^{2} /$ Size of the earthing, $\mathrm{m}^{2}$ \\
\hline 1.14 & $\mathrm{X}$ & $\begin{array}{l}\text { Тип заземлителя (вертикальный-стержневой, горизонтальный) / Earthing type (vertical- } \\
\text { rod, horizontal) }\end{array}$ \\
\hline 1.15 & $\mathrm{X}$ & Высота молниеотвода, м / Height of the lightning conductor, $\mathrm{m}$ \\
\hline 1.16 & $\mathrm{X}$ & Материал элементов молниеотвода / Material of the elements of a lightning conductor \\
\hline 1.17 & $\mathrm{X}$ & $\begin{array}{l}\text { Место расположения молниеотвода на/возле объекта защиты / Location of the lighting } \\
\text { conductor on/near the protected facility }\end{array}$ \\
\hline 1.18 & $\mathrm{X}$ & Время года / Season \\
\hline 1.19 & $\mathrm{X}$ & $\begin{array}{l}\text { Удельная пожарная нагрузка в здании, сооружении / Fire load in the building, } \\
\text { construction }\end{array}$ \\
\hline 1.20 & $\mathrm{X}$ & Горючесть кровельного материала / Flammability of the roofing material \\
\hline \multicolumn{3}{|r|}{ 2. . Факторы типа Z / Factors type Z } \\
\hline 2.1 & $\mathrm{Z}$ & Пожарная нагрузка объекта защиты, мДж/м² / Fire load of the protected facility, mJ/m² \\
\hline 2.2 & $\mathrm{Z}$ & Сила тока молнии, КА / Electric current from a lightning strike, KA \\
\hline 2.3 & $\mathrm{Z}$ & Напряжение молнии, КВ / Voltage of a lightning strike, KV \\
\hline 2.4 & $\mathrm{Z}$ & Частота удара молнии, удар/км² / The frequency of lightning strikes / km² \\
\hline 2.5 & $\mathrm{Z}$ & $\begin{array}{l}\text { Безопасное расстояние от объекта защиты до молниеотвода, м / Safe distance from the } \\
\text { protected facility to the lightning conductor, m }\end{array}$ \\
\hline 2.6 & $\mathrm{Z}$ & $\begin{array}{l}\text { Надлежащее обслуживание и контроль молниезащиты / Proper maintenance and control } \\
\text { of the lightning conductor }\end{array}$ \\
\hline 2.7 & $\mathrm{Z}$ & $\begin{array}{l}\text { Значение сопротивления заземлителя молниеотвода, определенное инструментальным } \\
\text { способом через промежуток времени: день/неделя/месяц, Ом / The resistance value of } \\
\text { earthing, calculated with the use of an instrument in a time period: day / week / month, } \Omega\end{array}$ \\
\hline \multicolumn{3}{|r|}{ 3. Факторы типа Q / Factors type Q } \\
\hline 3.1 & Q & Полярность молнии / Polarity of a lightning strike \\
\hline 3.2 & Q & Высота удара молнии, м / Height of a lightning strike, m \\
\hline 3.3 & $Q$ & Психофизические особенности человека / Psychophysical features of a human \\
\hline
\end{tabular}

Источник: Собственная разработка.

Source: Own elaboration.

При выборе определялись «значимые» и «незначимые» факторы, качественные и количественные. К «значимым» относились факторы, указывающие на причину возникновения пожара. Данные факторы подразумевали собой характеристики строительных конструкций, планировочные решения объекта защиты, способы молниезащиты, характеристики молниеотвода и т.п.

\section{3. Проведение пассивного эксперимента}

Анализ статистических данных о пожарах на объектах агропромышленного комплекса и собственный опыт позволяют сделать вывод, что устойчивое функционирование объекта к возникновению пожаров от грозовых разрядов зависит от большого количества факторов различной природы. Это обстоятельство делает целесообразным постановку отсеивающих экспериментов, позволяющих на первом этапе исследований выявить наиболее существенные факторы, влияющие на устойчивое функционирование объекта к возникновению пожаров от грозовых разрядов (параметр $Y$ ) [4]: $Y=1-\frac{n_{\text {пож}}}{N_{\text {пор }}}$

где $n_{\text {пож }}$ - возникающие пожары на объекте;

$N_{\text {пор }}$ - общее количество грозопоражений.

В таблице 2 приведены факторы, различная комбинация которых оказывает влияние на параметр Y. Два фактора количественные - $\mathrm{X}_{1}$ (степень огнестойкости объекта) и $\mathrm{X}_{2}$ (высота здания), один качественный - $\mathrm{X}_{3}$ (расположение молниеотвода). При этом под отдельно стоящим молниеотводом считается молниеотвод, расположенный на расстоянии от трех и более метров от защищаемого здания или сооружения. 
Таблица 2. Натуральные и нормированные значения факторов устойчивого функционирования объекта АПК при воздействии грозовых разрядов

Table 2. Dietary factors and the normalized values of sustainable operation of the facility under the influence of agribusiness lightning

\begin{tabular}{|c|c|c|}
\hline \multirow[t]{2}{*}{$\begin{array}{l}\text { Наименование фактора / } \\
\text { Name of the factor }\end{array}$} & \multicolumn{2}{|c|}{$\begin{array}{l}\text { Нормированные значения факторов } X_{r} / \\
\text { Normalized values of the factors } X_{r} \\
r=1,2,3\end{array}$} \\
\hline & $X_{r}=+1$ & $X_{r}=-1$ \\
\hline $\begin{array}{l}\text { 1. Степень огнестойкости объекта / Fire } \\
\text { resistance of the facility [5] }-x_{1}\end{array}$ & I - IV & V - VIII \\
\hline $\begin{array}{l}\text { 2. Высота здания / } \\
\text { Height of a building }-x_{2}, \text { м }\end{array}$ & $\leq 5$ & $>5$ \\
\hline $\begin{array}{l}\text { 3. Расположение молниеотвода / } \\
\text { Location of a lightning conductor } \mathrm{g}-x_{3}\end{array}$ & отдельностоящий / separate & $\begin{array}{c}\text { расположенный в застройке / } \\
\text { located in a building }\end{array}$ \\
\hline
\end{tabular}

Источник: Собственная разработка.

Source: Own elaboration.

Для постановки отсеивающего эксперимента был взят план полного факторного эксперимента типа $2^{3} \mathrm{c}$ количеством опытов $N=2^{3}=8$ и числом дублей в каждом опыте $n=3$. В результате обработки данных методами математической статистики [6] получено адекватное уравнение регрессии первого порядка:

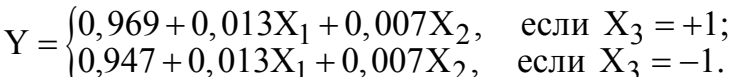

Анализ результатов отсеивающего эксперимента на первом этапе позволил сделать следующие выводы:

a) молниеотвод, стоящий отдельно от защищаемого объекта $\left(X_{3}=+1\right)$, эффективнее, чем молниеотвод, расположенный непосредственно на объекте $\left(X_{3}=-1\right)$

6) максимальное устойчивое функционирование объекта к возникновению пожаров от грозовых разрядов ( $\approx 99 \%)$ достигается в том случае, если объект относится к I - IV степени огнестойкости $\left(X_{1}=+1\right)$, а его высота не превышает 5 м $\left(X_{2}=+1\right)$.

На втором этапе исследований была поставлена задача - создать математическую модель, которая позволит прогнозировать эффективность функционирования молниеотвода. Предварительные исследования, а также анализ статистических данных пожаров в Республике Беларусь за последние 10 лет позволили установить наиболее существенные факторы - коэффициент защиты молниеотвода (отношение высоты зоны защиты молниеотвода к высоте объекта защиты); коэффициент сопротивления заземлителя (отношение длины заземлителя к нормируемому сопротивлению заземления); площадь сечения молниеотвода, влияющие на этот процесс (рис. 1), а также установить уровни и интервалы их варьирования (табл. 3).

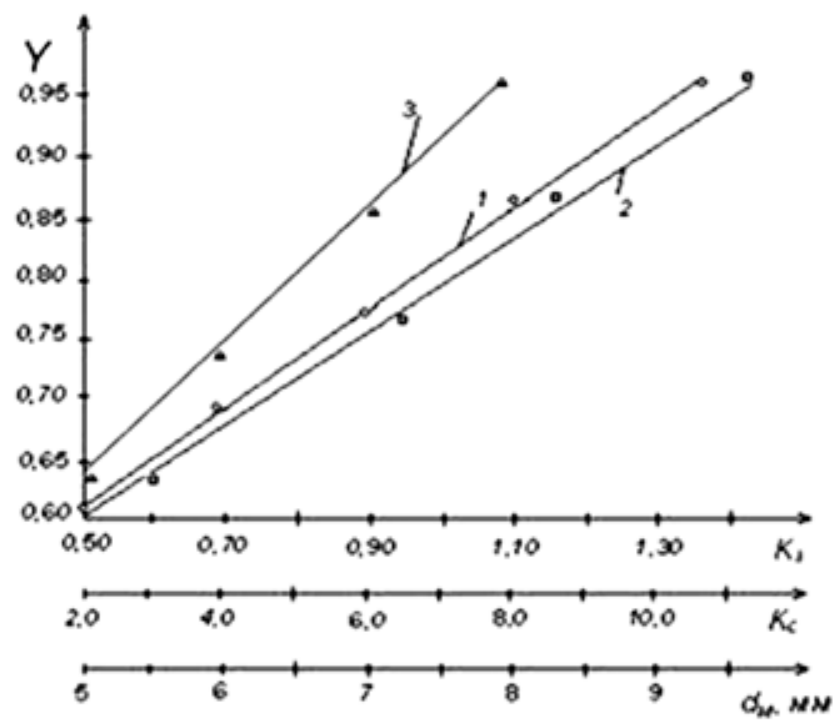

Рис.1 Эффективность молниеотвода в зависимости от:

1 - коэффициента защиты молниеотвода (Кз); 2 - коэффициента сопротивления заземлителя (Кс);

3 - диаметра сечения молниеприемника (dм), мм.

Fig. 1. Effectiveness of a lightning conductor according to:

1 - lightning conductor's protection factor $(\mathrm{Kz}) ; 2$ - earthing resistance coefficient (Ks); 3 - the diameter of the lightning conductor $(\mathrm{dm}), \mathrm{mm}$.

Источник: Собственная разработка.

Source: Own elaboration. 
Таблица 3. Наименование факторов, уровни и интервалы их варьирования, влияющих на эффективность работы молниеотвода

Table 3. Factors influencing the effectiveness of a lighting conductor's work, and the levels and intervals of their variation

\begin{tabular}{|c|c|c|c|}
\hline $\begin{array}{c}\text { Наименование } \\
\text { факторов / Name of } \\
\text { the factor }\end{array}$ & $\begin{array}{c}\text { Коэффициент защиты } \\
\text { молниеотвода, Кз / } \\
\text { Lightning protection } \\
\text { coefficient, Kz } \\
\end{array}$ & $\begin{array}{c}\text { Коэффициент сопротивления } \\
\text { заземлителя, Кс, м/Ом / } \\
\text { Earthing resistance coefficient } \\
\text { Ks, } \mathbf{m} / \Omega \\
\end{array}$ & $\begin{array}{c}\text { Площадь сечения молниеотвода, } \\
\mathrm{S}_{\mathrm{m}}=3,14 \times(\mathrm{dm} / 2)^{2}, \mathrm{~mm}^{2} / \\
\text { Cross-sectional area of the } \\
\text { lightning conductor, } \mathrm{dm}, \mathrm{mm}^{2} \\
\end{array}$ \\
\hline $\begin{array}{l}\text { Основной уровень / } \\
\text { Basic level, } x_{r 0}\end{array}$ & 0,96 & 6,7 & 30 \\
\hline $\begin{array}{l}\text { Интервал } \\
\text { варьирования / The } \\
\text { interval of variation, } \Delta x_{r}\end{array}$ & 0,4 & 4,8 & 20 \\
\hline $\begin{array}{l}\text { Верхний уровень / } \\
\text { Top level, } X_{r}=+1\end{array}$ & 1,36 & 11,5 & 50 \\
\hline $\begin{array}{l}\text { Нижний уровень / } \\
\text { Lower level, } X_{r}=-1\end{array}$ & 0,56 & 1,9 & 10 \\
\hline $\begin{array}{l}\text { Формулы перевода } \\
\text { натуральных } \\
\text { значений факторов } \\
\text { в нормированные и } \\
\text { обратно / Equations } \\
\text { for the conversion } \\
\text { of natural values } \\
\text { of the factors into } \\
\text { the normalized and } \\
\text { backwards }\end{array}$ & $\begin{array}{c}X_{1}=\frac{x_{1}-0,96}{0,4} \\
\mathrm{x}_{1}=0,96+0,4 \cdot \mathrm{X}_{1}\end{array}$ & $\begin{array}{c}X_{2}=\frac{x_{2}-6,7}{4,8} \\
x_{2}=6,7+4,8 \cdot X_{2}\end{array}$ & $\begin{array}{l}X_{3}=\frac{x_{3}-30}{20} \\
x_{3}=30+20 \cdot X_{3}\end{array}$ \\
\hline
\end{tabular}

Источник: Собственная разработка.

Source: Own elaboration.

Моделирование изучаемого объекта выполнялось с помощью трёхфакторного неполного квадратного уравнения регрессии [6]:

$$
\begin{aligned}
Y & =b_{0}+b_{1} X_{1}+b_{2} X_{2}++b_{3} X_{3}+ \\
& +b_{12} X_{1} X_{2}+b_{13} X_{1} X_{3}+b_{23} X_{2} X_{3}
\end{aligned}
$$

где $b_{0}, b_{1}, b_{2}, b_{3}, b_{12}, b_{13}, b_{23}$-коэффициенты уравнения регрессии

Для нахождения коэффициентов приведенного уравнения регрессии использовался план полного факторного эксперимента (ПФЭ) с числом опытов $N_{3}=2^{3}=8$. План ПФЭ, в котором факторы ортогональны

$\left(\sum_{j=1}^{N} X_{r j} X_{s j}=0\right)$

позволяет произвести независимую оценку коэффициентов многофакторного уравнения регрессии и дисперсий их значимости.

В таблице 4 приведены экспериментальные данные и результаты их обработки методами математической статистики.

Таблица 4. Результаты эксперимента для $k=3$

\begin{tabular}{|c|c|c|c|c|c|c|c|}
\hline$N$ & $Y_{l j}$ & $Y_{2 j}$ & $Y_{3 j}$ & $\overline{Y_{j}}$ & $\mathrm{~S}_{\mathrm{i}}^{2}$ & $\mathrm{Y}_{\mathrm{j}}^{\mathrm{p}}$ & $\left(\overline{Y_{j}}-Y_{j}^{p}\right)^{2}$ \\
\hline 1 & 0,605 & 0,590 & 0,610 & 0,602 & $1,08 \cdot 10^{-4}$ & 0,598 & $1,41 \cdot 10^{-5}$ \\
\hline 2 & 0,780 & 0,780 & 0,820 & 0,793 & $5,33 \cdot 10^{-4}$ & 0,793 & $6,94 \cdot 10^{-5}$ \\
\hline 3 & 0,720 & 0,705 & 0,730 & 0,718 & $1,58 \cdot 10^{-4}$ & 0,718 & $6,94 \cdot 10^{-5}$ \\
\hline 4 & 0,910 & 0,919 & 0,900 & 0,910 & $9,03 \cdot 10^{-5}$ & 0,914 & $1,53 \cdot 10^{-5}$ \\
\hline 5 & 0,660 & 0,645 & 0,665 & 0,657 & $1,08 \cdot 10^{-4}$ & 0,658 & $8,4 \cdot 10^{-5}$ \\
\hline 6 & 0,850 & 0,840 & 0,860 & 0,850 & $1,00 \cdot 10^{-4}$ & 0,853 & $8,51 \cdot 10^{-5}$ \\
\hline 7 & 0,775 & 0,765 & 0,785 & 0,775 & $1,00 \cdot 10^{-4}$ & 0,778 & $8,51 \cdot 10^{-5}$ \\
\hline 8 & 0,980 & 0,970 & 0,990 & 0,980 & $1,00 \cdot 10^{-4}$ & 0,973 & $4,56 \cdot 10^{-5}$ \\
\hline \multicolumn{6}{|c|}{$\sum_{j=1}^{8} S_{j}^{2}=1,299 \cdot 10^{-3}$} & \multicolumn{2}{|c|}{$\varphi=\sum_{j=1}^{8}\left(\overline{Y_{j}}-Y_{j}^{p}\right)^{2}=9,283 \cdot 10^{-5}$} \\
\hline
\end{tabular}

Table 4. Experimental results for $k=3$

Источник: Собственная разработка.

Source: Own elaboration. 
В результате статистической обработки результатов эксперимента установлено:

a) все восемь выборочных дисперсий $\mathrm{S}_{\mathrm{j}}^{2}$ однородны по критерию Кохрена, так как $G_{3}<G_{n-1 ;} ;$; 0,95, где $G_{3}=\max S_{j}^{2} / \sum_{j=1}^{N} S_{j}^{2}=\frac{5,333 \cdot 10^{-4}}{1,299 \cdot 10^{-3}}=0,411$

- экспериментальное значение критерия Кохрена, $G_{2 ; 8 ; 0,95}=G_{n-1 ; N ; p}=0,516-$ критическое значение критерия Кохрена при числе степеней свободы $f_{\text {числ }}=n-1, f_{\text {знам }}=N_{\text {и доверительной вероятно- }}$ сти $p=0,95$ [6];

б) так как выборочные дисперсии однородны, то дисперсия воспроизводимости и её число степеней свободы $f$ определяются по следующим уравнениям:

$$
\begin{aligned}
& S_{\text {воспр }}^{2}=\frac{\sum_{j=1}^{N} S_{j}^{2}}{N}=\frac{1,299 \cdot 10^{-3}}{8}=1,624 \cdot 10^{-4} \\
& f=N(n-1)=8 \cdot(3-1)=16 ;
\end{aligned}
$$

в) коэффициенты уравнения регрессии, рассчитанные по формулам (4) - (6)

$b_{0}=\frac{\sum_{j=1}^{8} \bar{Y}_{j}}{8}$

$b=\frac{\sum X_{r j} \bar{Y}}{r=1,2,3}$

$b_{r s}=\frac{\sum_{\substack{j=1 \\ r<s}}^{8} X_{r j} X_{s j} \bar{Y}_{j}}{8}, \quad r, s=1,2,3$

равны:

$b_{0}=0,7856 ; b_{1}=0,0977, b_{2}=0,0602, b_{3}=0,0298$, $b_{12}=0,0014, b_{13}=0,0019, b_{23}=0,0019$.

г) доверительный интервал всех коэффициентов уравнения регрессии, равен

$$
\begin{aligned}
\Delta b & =t_{N(n-1) ; p} \cdot \sqrt{\frac{S_{\text {воспр }}^{2}}{n \cdot N}}=2,120 \cdot \sqrt{\frac{1,624 \cdot 10^{-4}}{3 \cdot 8}}= \\
& =5,514 \cdot 10^{-3} \approx 6 \cdot 10^{-3}
\end{aligned}
$$

поэтому коэффициенты $b_{0}, b_{1}, b_{2}, b_{3}$ трехфакторного уравнения регрессии значимы по критерию Стьюдента, так как $\Delta b<b_{r}(r=0,1,2,3)$, а коэффициенты $b_{12}, b_{13}, b_{23}$ незначимы, так как $\Delta b>b_{r s}(r, s=1,2,3, r<s)$, где $t_{\text {табл }}=t_{N(n-1), p}=t_{16,0,95}=2,120$ - табличное значение критерия Стьюдента при числе степеней свободы $f=N(n-1)=16$ и доверительной вероятности $p=0,95[6]$

д) полученное трехфакторное уравнение регрессии адекватно [6], так как $F_{3}<F_{\text {табл }}$, где:

$S_{\text {ад }}^{2}=\frac{n \varphi}{N-B}=\frac{3 \cdot 9,283 \cdot 10^{-5}}{8-4}=6,962 \cdot 10^{-5}$, $f_{\text {ад }}=N-B=8-4=4$;

$F_{3}=\frac{S_{\text {воспр }}^{2}}{S_{\text {ад }}^{2}}=\frac{1,624 \cdot 10^{-4}}{6,962 \cdot 10^{-5}}=2,333$,

так как $S_{\text {воспр }}^{2}>S_{\text {ад }}^{2}$;

$F_{\text {табл }}=F_{N(n-1) ; N-B ; 0,95}=F_{18 ; 4 ; 0,95}=5,844$,

где $F_{N(n-1) ; N-B ; 0,95}=F_{16 ; 4 ; 0,95}=5,844$ - табличное значение критерия Фишера при числе степеней свободы $f_{\text {числ }}=N(n-1)=16, f_{\text {знам }}=N-B=4$ (В - число значимых коэффициентов регрессии $B=4)$ и доверительной вероятности $p=0,95$;

е) относительная погрешность прогнозирования параметра $Y$ равна:

$\Delta Y=t_{N(n-1)} \sqrt{\frac{S_{\text {воспр }}^{2}}{n N}\left(1+X_{1}^{2}+X_{2}^{2}+X_{3}^{2}\right)}$

ж)с учетом вышеизложенного, уравнение (3) примет следующий вид:

$Y=0,786+0,098 \cdot X_{1}+0,060 \cdot X_{2}+0,030 \cdot X_{3}$.

Максимальное значение параметра Ү достигается при $X_{1}=+1, X_{2}=+1, X_{3}=+1$ и равно согласно уравнениям (7) - (8) $Y_{\max }=0,974 \pm 0,011$.

3) перевод нормированных значений факторов в натуральные осуществляем по формулам, приведенным в таблице 2. Максимальная эффективность функционирования молниеотвода достигается при $K_{3}=1,36, K_{\mathrm{c}}=11,5, d_{\mathrm{M}}=50 \mathrm{Mм}$.

\section{4. Натурные наблюдения за молниеотводом}

Патентный поиск [7-9] позволил сделать выводы, что авторами разработок в области молниезащиты в меньшей степени уделено внимание функции устойчивости молниеотводов при воздействии на них таких внешних природных факторов (устойчивое функционирование молниеотвода) и в большей степени уделено внимание их функциональной (прием тока молнии) и эстетической составляющей. С учетом проведенных результатов исследований по устойчивому функционированию объекта к возникновению пожаров от грозовых разрядов, анализа патентов, возможно разрешить вопрос в проблематике применения не всегда эффективных мер молниезащиты в традиционной молниезащите объектов АПК. Эскизный вариант молниеотвода с повышенными характеристиками устойчивого функционирования, приведен на рисунке 2. 


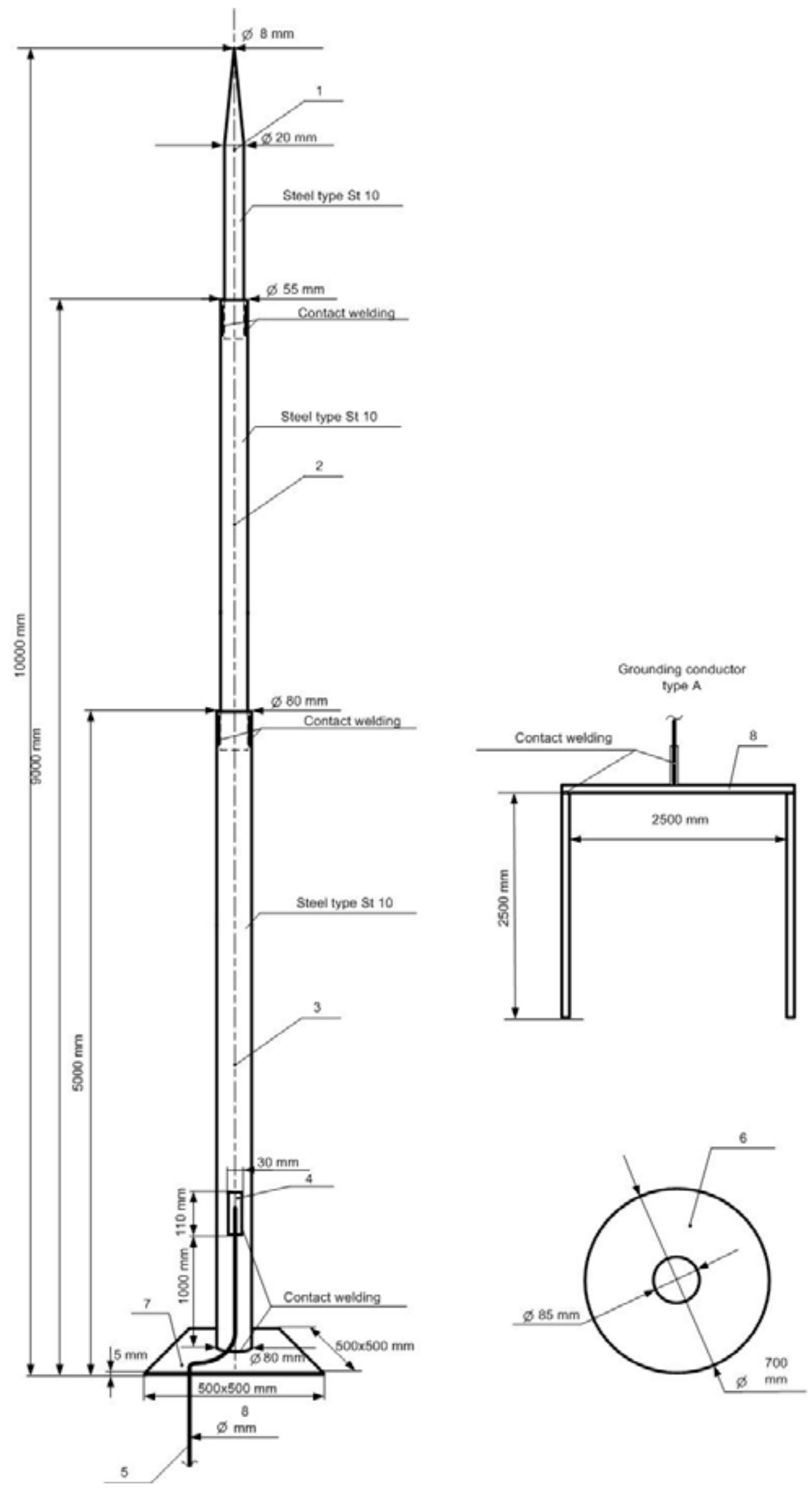

Рис. 2. Молниеотвод с повышенными характеристиками устойчивости функционирования

Fig. 2. A lightning conductor with enhanced resistance level Источник: Собственная разработка. Source: Own elaboration. 
Молниеотвод должен быть отдельно стоящим и состоять из следующих элементов: молниеприемник, токоотвод и заземлитель. Высота молниеотвода 10 м. Молниеприемник должен быть изготовлен из стали типа Ст10 или Ст8, оцинкованной стали. Состоит из верхней (1), средней (2) и нижней части (3), расположенной у основания молниеотвода. Диаметр сечения мачты у основания молниеотвода должен составлять не менее 80 мм, у верхушки мачты - не менее 8 мм, в средней части - не менее 55 мм. У основания мачты должно быть предусмотрено место контактного соединения (4), которое располагается на высоте не менее 1 м от нулевой отметки молниеотвода. Контактное соединение представляет собой прямоугольную пластину из стали Ст10 размерами $3 \times 11$ см и предназначено для присоединения заземления к мачте через гибкий круглый токопроводник (5) диаметром не менее 8 мм (или из полосовой стали с поперечным сечением не менее 33 мм²$^{2}$ ). Способ соединения частей молниеотвода между собой должен осуществляется посредством контактной сварки внахлест. Длина сварного шва между мачтой молниеотвода и контактным соединением должна быть не менее шестикратного диаметра круглых проводов или двойной ширины прямоугольных полос. Площадь контакта (между мачтой и гибким токопроводником) должна быть не менее удвоенной площади сечения токоотвода. С целью обеспечения устойчивости молниеотвод снабжается у основания мачты бетонным грузом (6) диаметром не менее 70 см и весом от 25 до 50 кг. Груз имеет форму неполной окружности. Внутренний диаметр оси груза должен быть на 5 мм (85 мм) сечения больше диаметра сечения основания молниеотвода с целью обеспечения практичного и быстрого крепления груза к мачте молниеотвода.

Для технического освидетельствования устойчивого функционирования молниеотвода потребовались наблюдения за ним: монтаж и получение информации о работоспособном состоянии молниеотвода, принятии своевременных профилактических мер, а так же проверка качества принятой техники монтажа и материалов изделия. В общем случае под термином устойчивого функционирования молниеотвода понималось изменение формы (высоты, длины, сечения, нарушения целостности, наклона) относительно первоначального положения (запроектированных осей или результатов первичных наблюдений). Наблюдения потребовали, в том числе, периодических и внеплановых осмотров, проводились согласно плану-графику исследований, но не реже одного раза неделю. Период наблюдений грозовой сезон 2014 года.

Для большей наглядности наблюдений составлялись пространственно-временные графики по наклонам и перекосам. Наблюдения за отклонением выполнялись при помощи фотосъемки и инструментального метода (при помощи теодолита).

Для проведения наблюдений была выбрана площадка в Минском районе. Координаты площадки: 53.9955556 широты, 27.68194440000002 долготы. На площадке размещаются солнечные батареи - аккумуляторной солнечной энергии. Площадка расположена в жилой застройке, на равнинной местности.

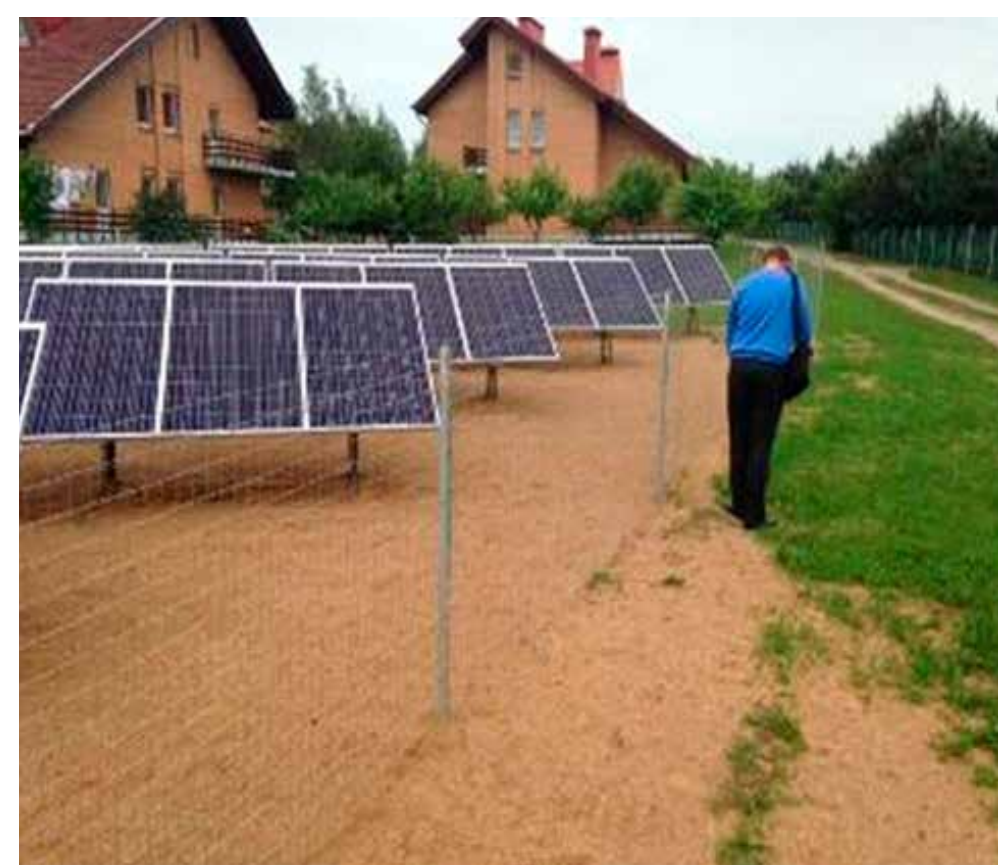

Рис. 3. Площадка для проведения исследований молниеотвода в д. Боровляны Минского района перед монтажом молниеотвода с повышенными характеристиками устойчивого функционирования

Fig. 3. Place for testing a lightning conductor in the village of Borovlyany in Minsk region prior to installation of a lightning conductor with enhanced resistance level

Источник: Собственная разработка.

Source: Own elaboration. 


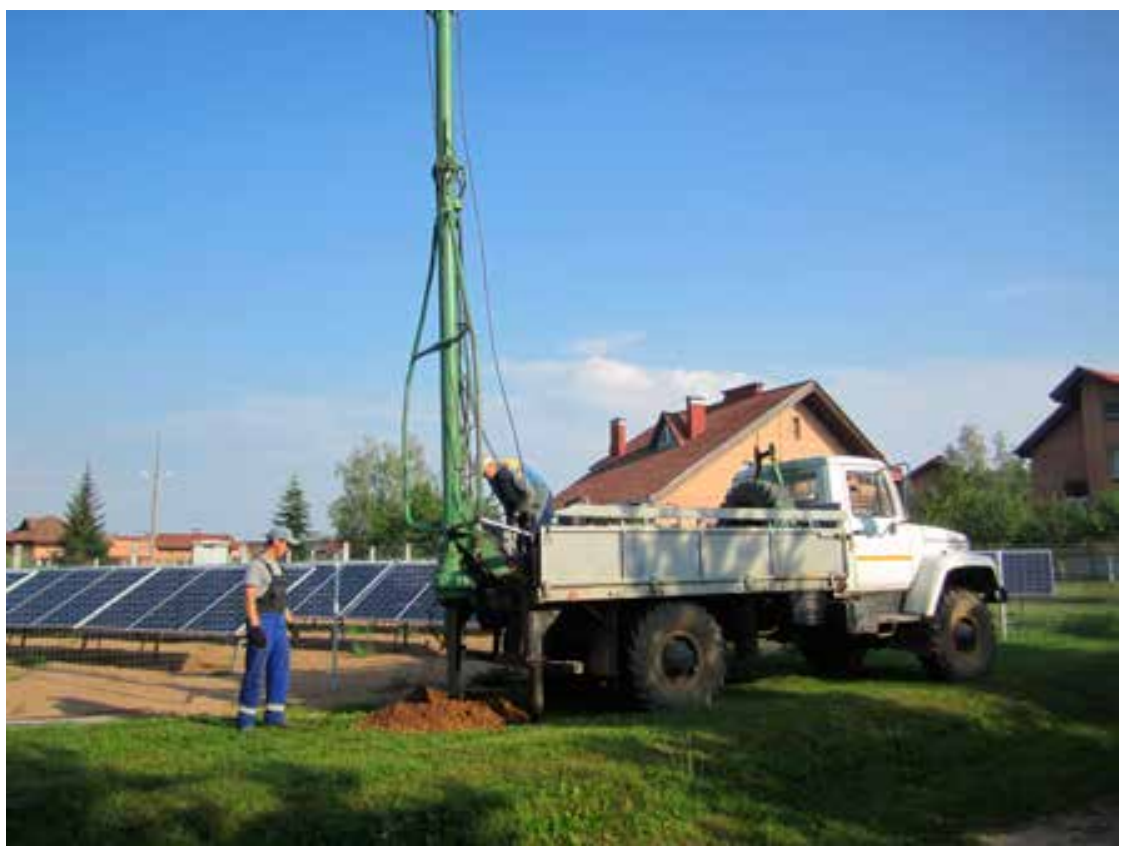

Рис. 4. Бурение скважины для монтажа молниеотвода с повышенными характеристиками устойчивого функционирования на площадке для проведения исследований в д. Боровляны Минского района

Fig. 4. Drilling for the installation of a lightning conductor with enhanced resistance level on the testing site in the village of Borovlyany, in Minsk region

Источник: Собственная разработка. Source: Own elaboration.

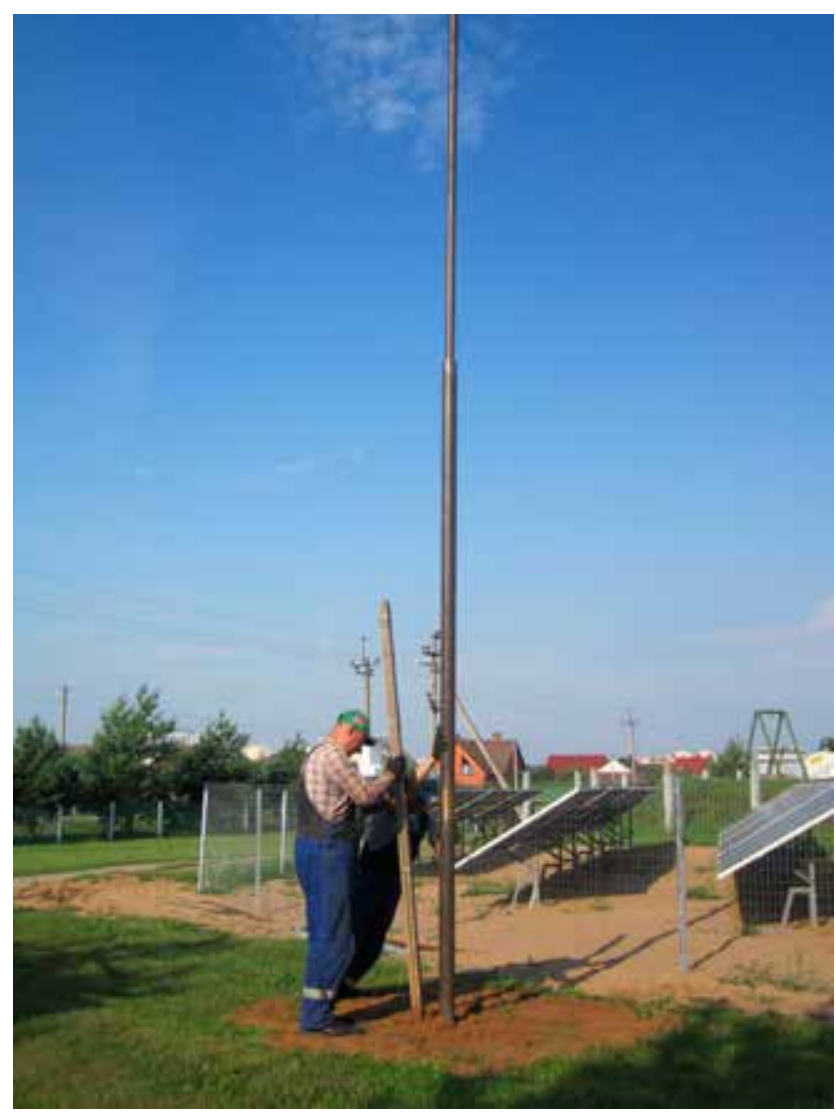

Рис. 5. Уплотнение грунта в месте установки молниеотвода с повышенными характеристиками устойчивого функционирования на площадке для проведения исследований в д. Боровляны Минского района

Fig. 5. Soil compaction in the place of installation of a lightning conductor with enhanced resistance level on the testing site in the village of Borovlyany, Minsk region

Источник: Собственная разработка. Source: Own elaboration. 


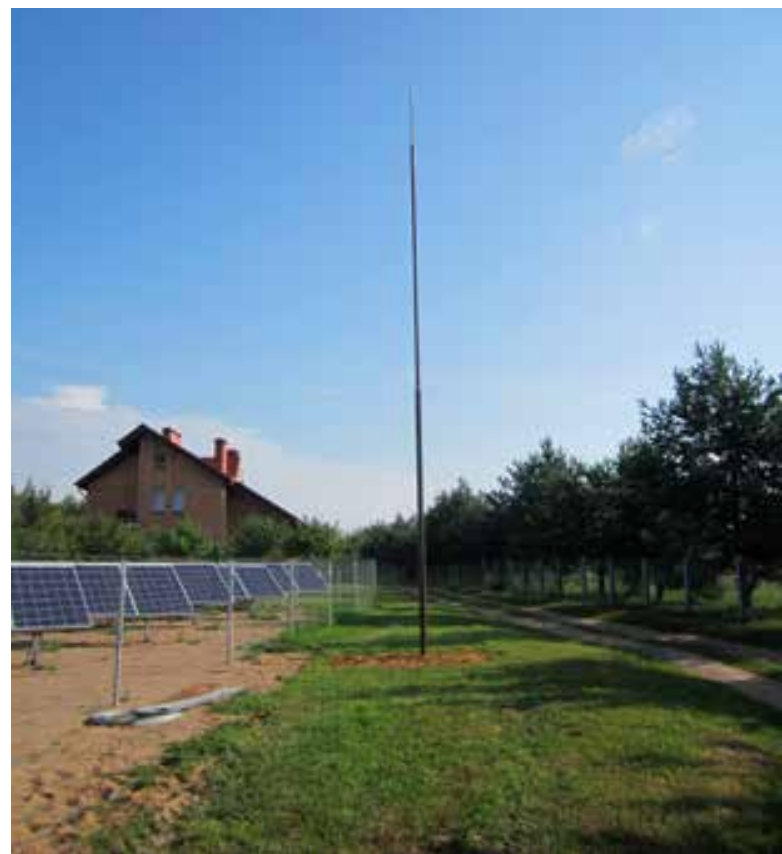

Рис. 6. Смонтированный молниеотвод с повышенными характеристиками устойчивого функционирования на площадке для проведения исследований в д. Боровляны Минского района в период наблюдений

Fig. 6. Mounted lightning conductor with enhanced resistance level on the testing site in the village of Borovlyany in Minsk region when observed

Источник: Собственная разработка.

Source: Own elaboration.

В таблице 4 приведены результаты предварительных наблюдений устойчивого функционирования молниеотвода на площадке для проведения исследований в д. Боровляны Минского района за период с июля по август 2014 года.

Таблица 5. Ведомость отметок наклонов и перекосов молниеотвода, размещенного на площадке для проведения исследований в д. Боровляны Минского района за период с июля по август 2014 года

Table 5. The statement of marks of bending and twisting of the lightning conductor, placed on a testing site in the village of Borovlyany in Minsk region for the period from July to August 2014

\begin{tabular}{|c|c|c|c|}
\hline \multicolumn{4}{|c|}{ Date of observation/type } \\
\hline № / No. of the measurement & $q_{x}, m m$ & $q_{y}, m m$ & $v_{\mathrm{cp}}, \mathrm{mm} /$ week \\
\hline \multicolumn{4}{|c|}{ 02.07.2014/primary } \\
\hline \multirow{2}{*}{1} & 7 & 29,5 & \multirow{2}{*}{$\begin{array}{l}v_{\mathrm{cpx}}=0 \\
v_{\mathrm{cpy}}=0\end{array}$} \\
\hline & 6,1 & $-0,4$ & \\
\hline \multicolumn{4}{|c|}{ 09.07.2014/ systematic } \\
\hline \multirow{2}{*}{2} & 7 & 29,73 & \multirow{2}{*}{$\begin{array}{c}v_{\text {cpx }}=0,09 \\
v_{\text {cpy }}=0,025\end{array}$} \\
\hline & 6,19 & $-0,425$ & \\
\hline \multicolumn{4}{|c|}{ 16.07.2014/ systematic } \\
\hline \multirow{2}{*}{3} & 7 & 29,5 & \multirow{2}{*}{$\begin{array}{c}v_{\text {cpx }}=0,16 \\
v_{\text {cpy }}=0,002\end{array}$} \\
\hline & 6,26 & $-0,427$ & \\
\hline \multicolumn{4}{|c|}{ 23.07.2014/ systematic } \\
\hline \multirow{2}{*}{4} & 7 & 29,5 & \multirow{2}{*}{$\begin{array}{c}v_{\mathrm{cpx}}=0,02 \\
v_{\mathrm{cpy}}=0,002\end{array}$} \\
\hline & 6,28 & $-0,429$ & \\
\hline \multicolumn{4}{|c|}{ 30.07.2014/ systematic } \\
\hline \multirow{2}{*}{5} & 7 & 29,5 & \multirow{2}{*}{$\begin{array}{c}v_{\text {cpx }}=0,02 \\
v_{\text {cpy }}=0,001\end{array}$} \\
\hline & 6,3 & $-0,43$ & \\
\hline \multicolumn{4}{|c|}{ 06.08.2014/systematic } \\
\hline \multirow{2}{*}{6} & 7 & 29,5 & \multirow{2}{*}{$\begin{array}{l}v_{\mathrm{cpx}}=0 \\
v_{\mathrm{cpy}}=0\end{array}$} \\
\hline & 6,3 & $-0,43$ & \\
\hline
\end{tabular}

Источник: Собственная разработка.

Source: Own elaboration. 


\section{5. Заключение}

1. Результаты проведенных исследований выявили факторы устойчивого функционирования объекта к возникновению пожаров от грозовых разрядов и показали, что максимальная устойчивость объекта к возникновению пожаров от грозовых разрядов достигается, когда здание высотой не более 5 метров относится к группе I - IV по степени огнестойкости и имеет отдельно установленный молниеотвод.

2. Для прогнозирования эффективной работы молниеотвода разработана математическая модель.
Установлено, что наилучшая молниезащита ( $\approx 97 \%)$ обеспечивается, когда молниеотвод имеет площадь сечения 50 мм², а значения коэффициентов защиты молниеотвода и сопротивления заземлителя равны 1,36 и 11,5 , соответственно.

3. По результатам исследований разработан эскиз и изготовлен молниеотвод с повышенными характеристиками устойчивого функционирования. Проводятся наблюдения за молниеотводом с целью уточнения его функциональной устойчивости.

\section{Литература}

[1] IEC 62305-3:2010 Protection against lightning - Part 3: Physical damage to structures and life hazard.

[2] IEC 62305-1:2010 Protection against lightning. - Part 1: General principles.

[3] Skripko A.N., Misun L.V., Dashkov V.N., Analiz vliyaniya grozovykh proyavleniy na pozharnuyu opasnost' zhivotnovodcheskikh ferm i kompleksov, , Chrezvychaynyye situatsii: preduprezhdeniye i likvidatsiya" Issue 1, 2012, pp. 37-43.

[4] Skripko A.N., Misun L.V., Leonov A.N., Issledovaniye zashchity ob"yektov APK ot vozdeystviya grozovykh razryadov, „Chrezvychaynyye situatsii: preduprezhdeniye i likvidatsiya" Vol. 33 Issue 1, 2013, pp. 70-77.

[5] TKP 45-2.02-142-2011 (02250) Zdaniya, stroitel'nyye konstruktsii, materialy i izdeliya.

[6] Leonov A.N., Dechko M.M., Lowkis V.B., Osnovy nauchnykh issledovaniy i modelirovaniya, BGATU, Minsk 2010, 276.

[7] Veb-sayt poleznaya model', http://poleznayamodel.ru [accessed: 16.05.2014].

[8] Veb-sayt findpatent.ru, http://www.findpatent.ru [accessed: 16.05.2014].

[9] Veb-sayt freepatent.ru, http://www.freepatent.ru [accessed: 19.05.2014].

[10] Veb-sayt patentdb.su, http://patentdb.su [accessed: 19.05.2014].

[11] Veb-sayt espacentet.com, http://ru.espacenet.com [accessed: 21.05.2014]

Скрипко Алексей Николаевич, начальник отдела исследований в области предупреждения чрезвычайных ситуаций учреждения „Научно-исследовательский институт пожарной безопасности и проблем чрезвычайных ситуаций” МЧС Республики Беларусь, соискатель степени кандидата технических наук, образование высшее. Автор и соавтор 1-го научного издания, 4-х научно-методических пособий, 2-х патентов на полезные модели, 15-ти публикаций в научных изданиях.

Мисун Леонид Владимирович, доктор технических наук, профессор, заведующий кафедрой „Безопасность жизнедеятельности” учреждения „Белорусский государственный аграрный технический университет”, образование высшее. Автор и соавтор 8-ми моногорафий, 1-го научного издания, 17-ти учебных и учебно-методических пособий, 28-ти патентов на изобретение, 175-ти публикаций в научных изданиях. 